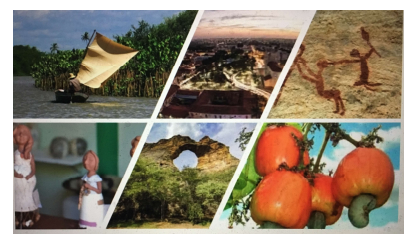

ISBN: 2675-1496 DOI: https://doi.org/10.26694/caedu.v1i2.9693

\title{
NA MARÉ DOS SCRIPTS DIGITAIS: O CARÁTER EDUCATIVO DA FANFICTION “TODO MUNDO ODEIA O CHRIS"
}

\author{
Robson Fonseca Simões \\ Doutor em Educação \\ Professor Adjunto da Universidade Federal de Rondônia \\ ORCID: http://orcid.org/0000-0003-0046-9549
}

\begin{abstract}
Resumo:
Numa tentativa de trazer para a discussão as postagens da página digital Fanfiction intitulada "Todo mundo odeia o Chris", este estudo procura privilegiar o âmbito educativo dessas práticas de escrita sobre o episódio televisivo homônimo no universo digital. As histórias contadas pelos sujeitos trazem à tona as suas representações, leituras, interpretações pessoais de mundo sobre as várias temáticas do cotidiano. Como num mosaico de experiências linguísticas, aquele site procura convidar os sujeitos a continuarem as aventuras vividas pelos personagens daquele episódio da televisão; agora quem é o autor da obra audiovisual é quem navega na internet. Os recursos da web, como numa coreografia digital, apresentam os seus movimentos na dança das novidades tecnológicas, o que pode instigar o sujeito a ver com outros olhos a modalidade de texto fan-fiction, que mergulha na maré dos gêneros digitais, das mídias e dos suportes das Tecnologias de Informação e Comunicação, tirando da sombra o debate sobre letramentos, as redes de sociabilidades e das emoções dos navegantes da internet diante da tela do computador.
\end{abstract}

Palavras-chave: Página Facfiction. Episódio televisivo "Todo Mundo odeia o Chris". Práticas de escrita.

\section{Abstract:}

In an attempt to bring to discussion the Fanfiction digital page posts entitled "Everyone Hates Chris", this study seeks to privilege the educational scope of these writing practices over the homonymous television episode in the digital universe. The stories told by the subjects bring out their representations, readings, personal interpretations of the world on the various themes of daily life. As in a mosaic of linguistic experiences, that site seeks to invite subjects to continue the adventures lived by the characters of that episode of television; Now the author of the audiovisual work is the one who browses the internet. The resources of the web, as in a digital choreography, present their movements in the

Revista Caminhos da Educação: diálogos, culturas e diversidades. CAEDU/UFPI 102

Teresina, Brasil, v. 1, n. 2, p. 102-116, maio/agosto de 2019.

ISBN: 2675-1496 DOI: https://doi.org/10.26694/caedu.v1i2.9693 


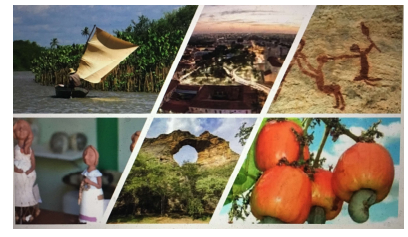

ISBN: 2675-1496 DOI: https://doi.org/10.26694/caedu.v1i2.9693

dance of technological novelties, which may entice the subject to see with other eyes the fan-fiction text modality, which plunges into the tide of digital genres, media and Information and Communication Technologies supports, taking the debate about literacy, social networks and emotions of Internet browsers out of the shadow of a computer screen.

Keywords: Facfiction Page. TV episode "Everyone Hates Chris". Writing practices.

\section{Resumen:}

En un intento por llevar a discusión las publicaciones de la página digital de Fanfiction tituladas "Todos odian a Chris", este estudio busca privilegiar el alcance educativo de estas prácticas de escritura sobre el episodio de televisión homónimo en el universo digital. Las historias contadas por los sujetos muestran sus representaciones, lecturas, interpretaciones personales del mundo sobre los diversos temas de la vida cotidiana. Como en un mosaico de experiencias lingüísticas, ese sitio busca invitar a los sujetos a continuar las aventuras vividas por los personajes de ese episodio de televisión; Ahora el autor de la obra audiovisual es el que navega por internet. Los recursos de la web, como en una coreografía digital, presentan sus movimientos en el baile de las novedades tecnológicas, que pueden atraer al sujeto a ver con otros ojos la modalidad de texto de fan-fiction, que se sumerge en la marea de géneros digitales, medios y de los apoyos de las Tecnologías de la Información y la Comunicación, sacando el debate sobre la alfabetización, las redes sociales y las emociones de los navegadores de Internet fuera de la sombra de una pantalla de computadora.

Palabras clave: Página de ficción. Episodio de televisión "Todo el mundo odia a Chris". Prácticas de escritura

Entre a televisão, a internet e a Educação: diálogos possíveis?

Revista Caminhos da Educação: diálogos, culturas e diversidades. CAEDU/UFPI 103

Teresina, Brasil, v. 1, n. 2, p. 102-116, maio/agosto de 2019.

ISBN: 2675-1496 DOI: https://doi.org/10.26694/caedu.v1i2.9693 


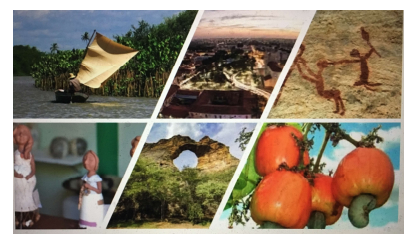

ISBN: 2675-1496 DOI: https://doi.org/10.26694/caedu.v1i2.9693

Chris Rock continua sendo um garoto afro-americano que mora no Brooklyn. A diferença é que no ano de 1983, coisas estranhas começaram a acontecer mais fora da escola; entre uma delas, sua primeira paixonite. ${ }^{1}$

A epígrafe deste estudo, com um trecho da narrativa criada pelo usuário da página digital Fanfiction intitulada "Todo mundo odeia o Chris", pode ser um ponto de partida para uma reflexão sobre o caráter educativo das práticas de escrita sobre o episódio televisivo homônimo no universo digital. Postadas na web, as histórias contadas podem trazer à tona as representações, leituras, interpretações pessoais de mundo sobre as várias temáticas do cotidiano. Como num mosaico de experiências linguísticas, aquele site procura convidar os sujeitos a continuarem as aventuras vividas pelos personagens daquele episódio da televisão; agora quem é o autor da obra audiovisual é quem navega na internet.

Não é difícil entender que as novas tecnologias têm provocado mudanças nas diversas atividades contemporâneas, sobretudo nos novos gêneros narrativos e formas eliterários (Marcuschi, 2008; Crystal, 2005; Lemos, 2008). Os recursos da web, como numa coreografia digital, apresentam os seus movimentos na dança das novidades tecnológicas, o que pode instigar o sujeito a ver com outros olhos a modalidade de texto fan-fiction, que mergulha na maré dos gêneros digitais, das mídias e dos suportes das Tecnologias de Informação e Comunicação, procurando tirar da sombra o debate sobre letramentos, das redes de sociabilidades e das novas sensibilidades dos navegantes da internet diante da tela do computador.

No tempo das tecnologias digitais, o usuário move-se sobre teclados, telas, (re)significando as funções e as relações do autor/leitor (Simões, 2018) com os textos no mundo contemporâneo. Nessa acepção, o campo das novas tecnologias, como sugere Lévy (1999), é aberto, conflituoso e parcialmente indeterminado, no qual nada está decidido a priori.

Refletir sobre a importância, o valor, os efeitos, as possibilidades da mídia no que tange à Educação, à formação dos sujeitos nas sociedades contemporâneas, estão também na pauta dos debates na Educação. Se por um lado, os seriados televisivos aparecem como possíveis protagonistas para aqueles que os consideram otimistas junto aos processos de formação cultural, por outro lado, na contramão deste debate, há os pessimistas de plantão, alegando ser a televisão uma causadora dos males sociais, responsável apenas pelos lucros das emissoras (Marcondes Filho, 1995). Seriam as obras audiovisuais veículos de alienação social dos sujeitos?

A escola e o professor questionam e são questionados sobre o papel que lhes cabe diante dos desafios suscitados por esse meio de comunicação, que vem tomando parte e alterando de modo significativo o cotidiano dos sujeitos e das sociedades (MartínBarbero, 1997). Um dos maiores desafios a serem enfrentados pela escolarização e pelos

${ }^{1}$ Escrita postada por Érico na página do site Fanfiction em 13/07/2012. Disponível em <https://fanfiction.com.br/historia/190761/Todo Mundo Odeia O Chris1983> Acesso em 29/10/2019. Revista Caminhos da Educação: diálogos, culturas e diversidades. CAEDU/UFPI 104

Teresina, Brasil, v. 1, n. 2, p. 102-116, maio/agosto de 2019.

ISBN: 2675-1496 DOI: https://doi.org/10.26694/caedu.v1i2.9693 


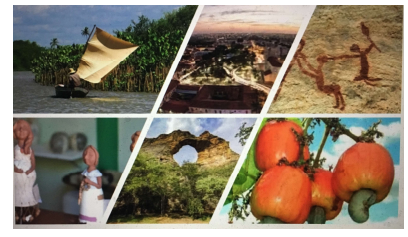

ISBN: 2675-1496 DOI: https://doi.org/10.26694/caedu.v1i2.9693

educadores talvez ainda seja o de aprofundar o conhecimento sobre como esta mídia possa operar influenciando na formação social dos sujeitos.

Se a voz de Guimarães Rosa (1985, p.74): "para estas duas vidas, um léxico só não é suficiente" também for invocada para este debate, quem sabe, seja para ajudar a oferecer um ângulo de visibilidade educativa na Fanfiction intitulada Todo mundo odeia o Chris, uma vez que naquele espaço virtual observam-se práticas de escrita com improvisação, com exercício de imaginação, composição de ideias, narrativas, ao poderem continuar as histórias dos personagens favoritos a partir das experiências linguísticas e culturais dos navegantes dessas páginas. Fiorin (2008) ajuda a pensar que o modo do uso linguístico está ligado aos processos sociais e culturais mais amplos; nesse sentido, é possível observar que ali as práticas de linguagem articulam palavras, sentidos, criam valores e práticas sociais a partir de uma cultura televisiva. (FISCHER, 2001)

As práticas de linguagem são habilidades sociais que, fazendo uso de diferentes discursos, além de significarem e comunicarem, abrem espaços para a polissemia (Sandmann, 1990) na medida em que permite múltiplas leituras; a polifonia (Bakhtin, 2000) se inscreve nesse ambiente de afirmação do heterogêneo, da multiplicidade de vozes, que se impõem por sua autenticidade, das várias vozes integrantes do projeto de fala do sujeito comunicante. É possível entender que a maior parte das práticas de linguagens televisivas (Fischer, 2001) procura capturar a todo o momento nossa atenção e nossas emoções. Sobre este comportamento, Machado (2007) faz uma observação fundamental para o entendimento das estratégias utilizadas pela televisão:

A televisão logra melhores resultados quando a sua programação é do tipo recorrente, circular, reiterando ideias e sensações a cada novo plano, ou então quando ela assume dispersão, estruturando sua programação em painéis fragmentários e híbridos, como nas colagens pictóricas ou nas revistas de variedades. (MACHADO, 2007, p.52)

A configuração textual que os seriados ficcionais assumem, pelo próprio compromisso com o entretenimento e despretensão com a objetividade e neutralidade, tende a favorecer a instituição de discursos lúdicos. Polifônicas, as vozes são marcadas pelo jogo (Barthes, 1999) de interlocuções entre os seus personagens; assim, o movimento dialógico (Bakhtin, 1999) entre os personagens se dinamiza numa dimensão plural, de forte caráter polissêmico.

Mas há quem pense diferente; para Ferrés (1996), a ficção é o gênero que tem a sua natureza ideológica. Nesse sentido, na narrativa, por intermédio dos mecanismos de identificação e projeção facilita-se a indução de condutas e valores éticos, culturais ou ideológicos. É possível refletir que mesmo em uma configuração textual despretensiosa, tendem a ser abertos espaços para dominação no discurso. Daí, a importância da escola,

Revista Caminhos da Educação: diálogos, culturas e diversidades. CAEDU/UFPI 105

Teresina, Brasil, v. 1, n. 2, p. 102-116, maio/agosto de 2019.

ISBN: 2675-1496 DOI: https://doi.org/10.26694/caedu.v1i2.9693 


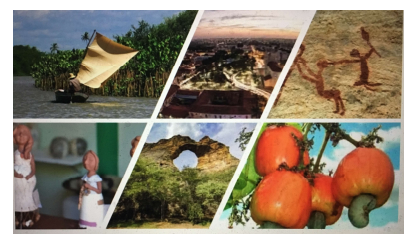

ISBN: 2675-1496 DOI: https://doi.org/10.26694/caedu.v1i2.9693

na condição de uma das principais instituições de formação cultural, e dos professores, como seus agentes, conhecerem mais sobre as práticas de linguagem nos vários repertórios de gêneros textuais e as suas possíveis contribuições linguísticas, o que pode nos aproximar do debate sobre o letramento. Mas o que é mesmo o letramento?

As reflexões de Soares (2009) sugerem que é preciso que os sujeitos saibam fazer uso da leitura e da escrita a fim de exercer cidadania de forma plena. Assim, o letramento é considerado como responsável por produzir resultados importantes: desenvolvimento cognitivo e econômico, mobilidade social, progresso profissional, cidadania.

Os estudos sobre as práticas de escrita nos remetem à Declaração de Persépolis ${ }^{2}$; assim concebido, o letramento cria estratégias para a aquisição de uma consciência crítica das contradições da sociedade em que os sujeitos vivem e dos seus objetivos; estimula a iniciativa e a participação dos sujeitos na criação de projetos capazes de atuar sobre o mundo, de transformá-lo e de definir os objetivos de um autêntico desenvolvimento humano. Não bastam as linguagens que os sujeitos dominam, trancadas no cotidiano de suas vidas; é preciso ler e escrever a outra, organizadora dos tempos e espaços sociais (Paiva, 2009) trabalhada em limites que não indaguem sobre a nossa compreensão da sociedade em que vivemos com todas as suas cores, sabores, conflitos, sentidos, textos. A condição de perceber/tratar a formação de leitores/autores, diferente do pensar em etapas dissociadas entre aprender a ler, provavelmente deverá afetar o modo como os sujeitos se dispõem a ler a vida.

Soares (2009) assume que é impossível definir letramento em um único conceito, pois os estudos históricos (Chartier, 2003) documentam as mudanças de concepção de letramento ao longo dos tempos, dependendo das crenças, dos valores e da história social de cada grupo. Alguns autores argumentam que seria mais adequado falar de letramentos no plural e não a um único letramento; pois, trata-se de um termo que envolve muitos significados.

Quem sabe, se ao invés de trabalharmos com línguas partidas, o que reforçaria a dicotomia entre as variantes culta e popular, seja possível considerar o amálgama das linguagens sociais e compreendê-las como manifestações enunciativas legítimas no trabalho escolar com as experiências individuais e sociais. (BARTHES, 1999)

As práticas educativas que procuram se debruçar no dialógico, que promova interações (Marcuschi, 2008) com os múltiplos universos culturais dos diferentes sujeitos aprendizes, exercitam a linguagem nas suas múltiplas manifestações. O que se propõe é refletir sobre práticas que privilegiem outros agrupamentos textuais, segundo recortes variados, em razão das demandas locais, culturais; por que não nos aproximarmos também das páginas virtuais Fanfiction?

\footnotetext{
${ }^{2}$ A Declaração de Persépolis considerou o letramento não apenas o processo de aprendizagem de habilidades de leitura, escrita, mas uma contribuição para a liberação do sujeito e para o seu pleno desenvolvimento.
}

Revista Caminhos da Educação: diálogos, culturas e diversidades. CAEDU/UFPI 106

Teresina, Brasil, v. 1, n. 2, p. 102-116, maio/agosto de 2019.

ISBN: 2675-1496 DOI: https://doi.org/10.26694/caedu.v1i2.9693 


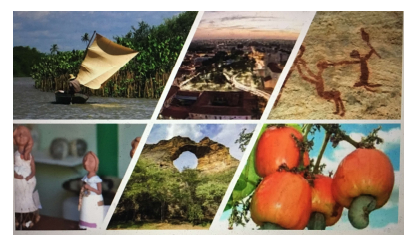

ISBN: 2675-1496 DOI: https://doi.org/10.26694/caedu.v1i2.9693

\section{Mergulhos na Fanfiction: narrativas em diálogos com a vida}

Atividades de produção de textos na internet também podem contribuir para a construção e a ampliação de conhecimentos dos sujeitos sobre como refletir sobre as temáticas do cotidiano, abrindo caminhos para também promover um ambiente profícuo à discussão, à superação de preconceitos linguísticos, das relações sociais, raciais e de gênero, procurando apresentar estas temáticas que também dialogam com a vida. A imagem a seguir com um trecho da narrativa da usuária Lívia pode contribuir para este debate.

Figura 1- Adaptação da Página Fanfiction "Todo mundo odeia o Chris"

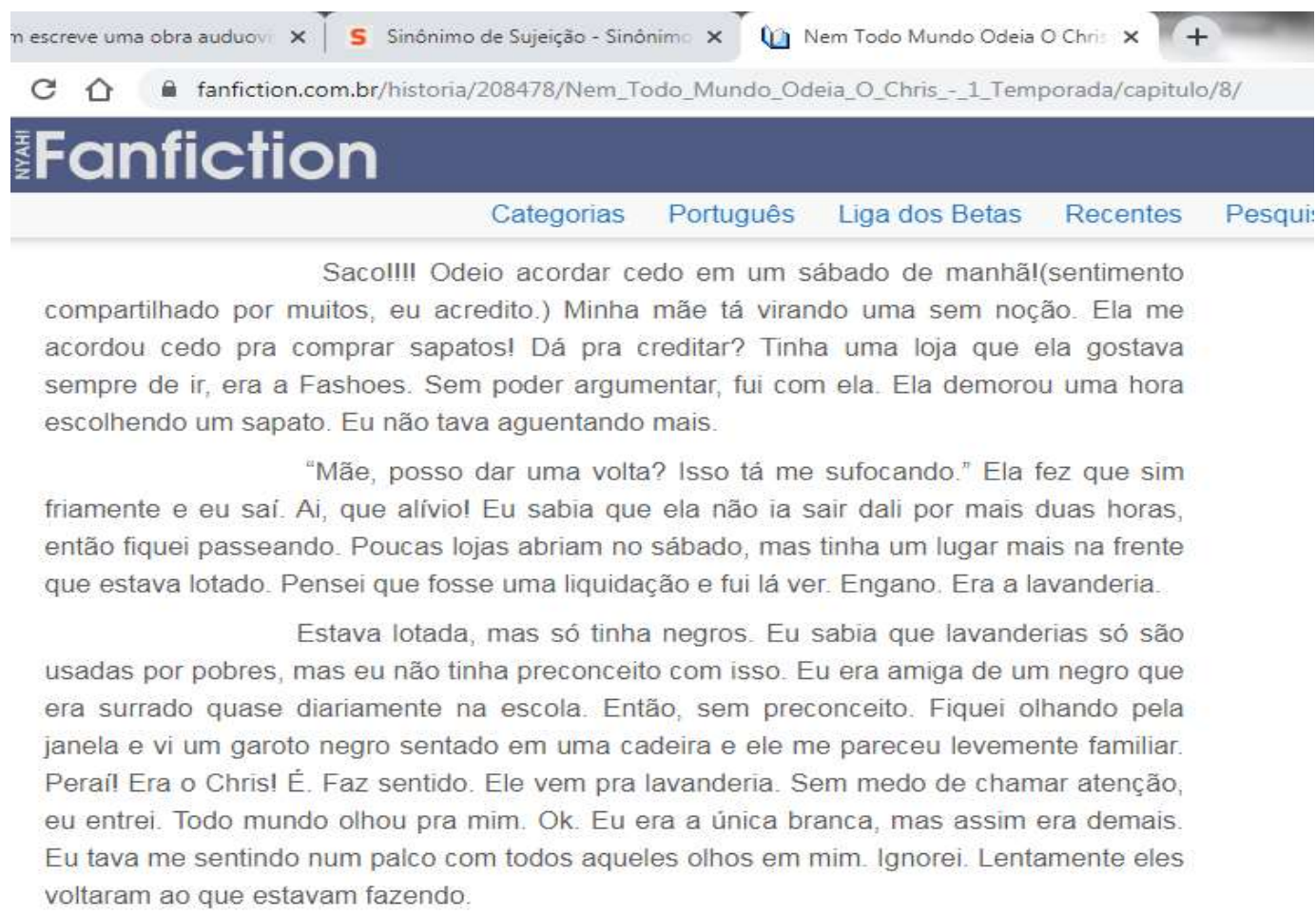

Fui na direção do Chris, ele tava dormindo. Sacudi ele de leve pra acordar.

Fonte: $<$ https://fanfiction.com.br/todomundoodeiaochris/>Acesso em 06/11/2019

Postada na página Todo mundo odeia o Chris, percebem-se na história contada pela usuária duas questões: a primeira de caráter linguístico, na qual a autora registra a variante Revista Caminhos da Educação: diálogos, culturas e diversidades. CAEDU/UFPI 107

Teresina, Brasil, v. 1, n. 2, p. 102-116, maio/agosto de 2019.

ISBN: 2675-1496 DOI: https://doi.org/10.26694/caedu.v1i2.9693 


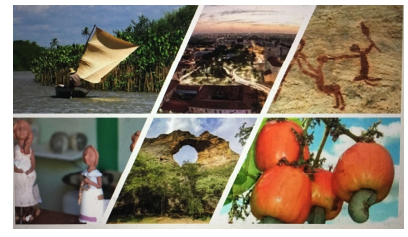

ISBN: 2675-1496 DOI: https://doi.org/10.26694/caedu.v1i2.9693

não formal da língua no seu texto; logo no início do parágrafo, examina-se a expressão: "Saco!!!!"; na modalidade oral, é muito utilizada quando os sujeitos estão nervosos, tratase, portanto, de uma construção linguística para os usos sociais. Os estudos de Bakhtin (2000) nos ajudam a compreender os feixes de sentidos que convivem nas palavras que se constroem, dialogam e disputam espaço, instaurando-as como signos ideológicos. Assim, nos movimentos dos sujeitos nas infindáveis situações de enunciação, os signos ou as palavras, pelo seu caráter vivo, polissêmico, têm sua significação determinada pelos contextos em que são produzidos.

Quando o assunto são as relações raciais e sociais, não é difícil examinar no mesmo quadro acima, mais especificamente no terceiro parágrafo do script criado pela usuária, a sua atenção ao comentar que as lavanderias só são utilizadas por pobres, mas a personagem não tinha preconceito com isso; além disso, registra que no mesmo espaço só havia pretos. O seu comentário abre portas para se discutirem sobre estes preconceitos sociais, fazendo andar o carrossel das reflexões das temáticas do cotidiano. Nessa acepção, é possível compreender que se tomarmos o gênero textual como uma voz situada histórica e socialmente, culturalmente sensível, recorrente, incorporando a consciência social dos sujeitos (Bakhtin, 2000), servindo como instrumento comunicativo com propósitos específicos, e como forma de ação social, é fácil perceber que um novo meio tecnológico deve também intervir na natureza do gênero produzido, abrindo um canal para se refletir sobre as temáticas. Esta leitura de mundo não é neutra e está relacionado à vida cotidiana, nas esferas da vida social, atravessadas pelas formas como a linguagem escrita as perpassa, de modo implícito ou explícito, de modo mais complexo ou menos complexo.

Os estudos de Marcuschi (2008) sugerem que os gêneros textuais são formas sociais de organização e expressões típicas da vida cultural e que a noção de gênero textual como fenômeno social e histórico não é nova; verifica-se que a temática vem sendo tratada, pesquisada e estudada desde os anos 60 quando surgiram a Linguística do Texto, Análise do Discurso. No entanto, o enfoque do domínio da mídia virtual é mais recente. Quem sabe, o ímã irresistível dos gêneros e narrativas nas páginas FunFiction irradie visibilidade para os que navegam na internet, como se pode examinar abaixo.

Figura 2- Adaptação da Página Fanfiction "Todo mundo odeia o Chris"

Revista Caminhos da Educação: diálogos, culturas e diversidades. CAEDU/UFPI 108

Teresina, Brasil, v. 1, n. 2, p. 102-116, maio/agosto de 2019.

ISBN: 2675-1496 DOI: https://doi.org/10.26694/caedu.v1i2.9693 


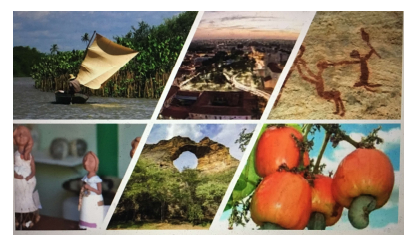

ISBN: 2675-1496 DOI: https://doi.org/10.26694/caedu.v1i2.9693

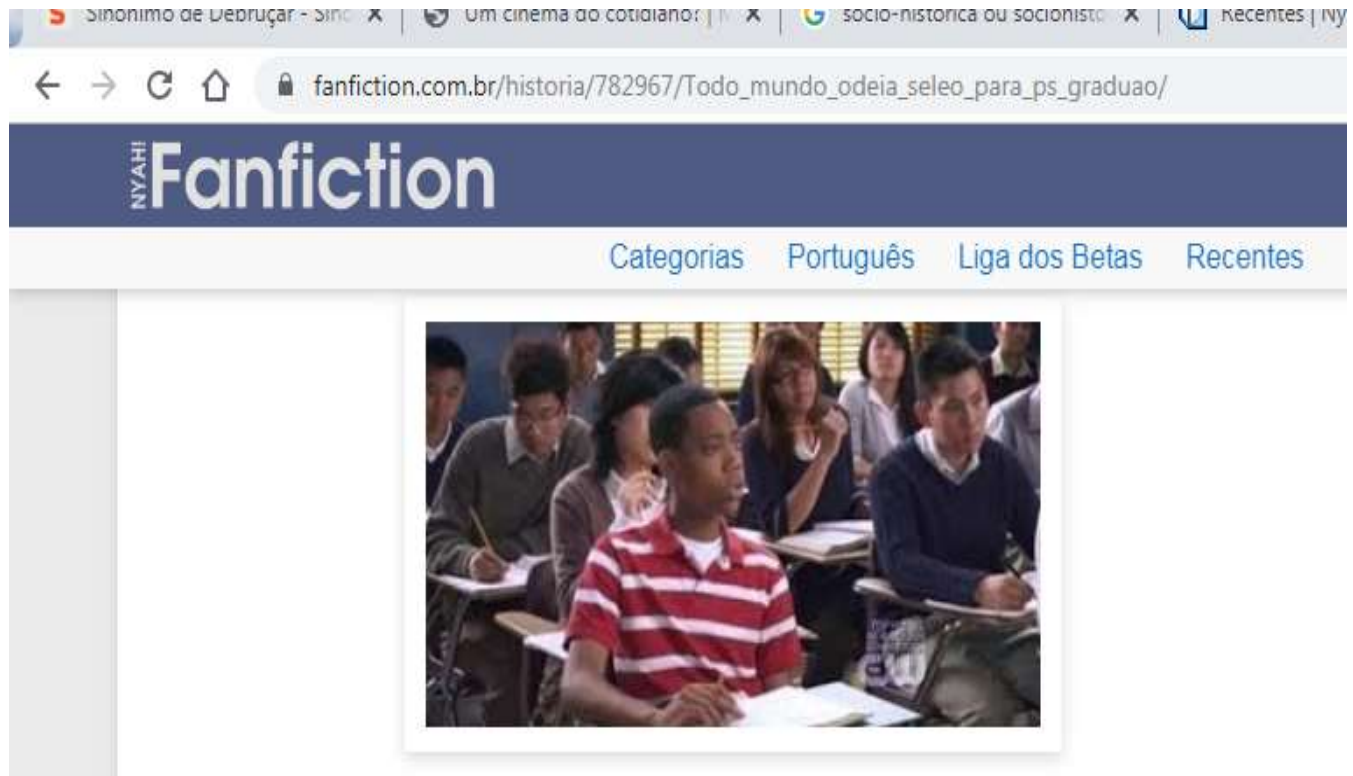

Chris, precisa tirar uma nota boa para entrar no mestrado em Linguistica, então decide se preparar para a seleção, mas quando Rochelle faz com que toda a familia participe de um evento social, Chris fica sem tempo para estudar e recebe uma proposta para comprar um gabarito com as respostas.

Fonte: $<$ https://fanfiction.com.br/todomundoodeiaochris/>Acesso em 06/11/2019

A figura acima escrita pelo usuário Ray, apresenta uma combinação inusitada com a alma da Pós-Graduação: vida acadêmica e humor. Nas entrelinhas, procura revelar a experiência do sujeito naqueles territórios; a continuação da história do seriado destaca uma versão que se aproxima da vida de um mestrando que pretende participar do processo seletivo para um Mestrado em Linguística. Bem humorado, o narrador procura (re)significar as histórias daquele seriado a partir de sua experiência na vida acadêmica. Crystal (2005) destaca os usos da natureza enunciativa dessa linguagem e dos gêneros realizados que se desenvolvem e se mesclam com vários outros, na tentativa de descobrir algo sobre o papel da linguagem na internet e o efeito da mesma na linguagem dos sujeitos.

Com o caráter das novas relações sociais (Marcuschi, 2008), o mundo das novas tecnologias aperfeiçoou novos espaços de comunicação, de sociabilidade (Aymard, 2009), de informação (Lévy, 1999), o que determinou também, consequentemente, a criação de novos espaços com as escritas dos sujeitos.

Por seu turno, Chartier (2003) destaca que com o texto eletrônico, parece estar ao alcance de nossos olhos e de nossas mãos um sonho muito antigo da humanidade, que se Revista Caminhos da Educação: diálogos, culturas e diversidades. CAEDU/UFPI 109

Teresina, Brasil, v. 1, n. 2, p. 102-116, maio/agosto de 2019.

ISBN: 2675-1496 DOI: https://doi.org/10.26694/caedu.v1i2.9693 


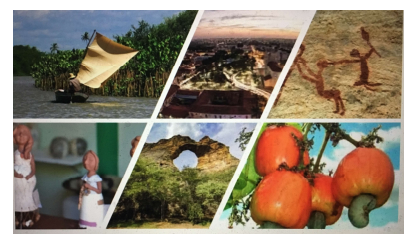

ISBN: 2675-1496 DOI: https://doi.org/10.26694/caedu.v1i2.9693

poderia resumir em duas palavras: universalidade e interatividade. Nesse sentido, podese supor uma nova caracterização do autor diante do advento do hipertexto eletrônico,

A leitura é sempre apropriação, invenção, produção de significados [...] o leitor é um caçador que percorre terras alheias. Apreendido pela leitura, o texto não tem de modo algum - ou ao menos totalmente - o sentido que lhe atribui seu autor, seu editor ou seus comentadores. Toda história da leitura supõe, em seu princípio, essa liberdade do autor que desloca e subverte aquilo que o livro the pretende impor. Mas esta liberdade leitora não é jamais absoluta. Ela é cercada por limitações derivadas das capacidades, convenções e hábitos que caracterizam, em suas diferenças, as práticas de leitura. Os gestos mudam segundo tempos e lugares, os objetos lidos e as razões de ler. Novas atitudes são inventadas, outras se extinguem. (CHARTIER, 2003, p. 236)

A textualidade eletrônica permite desenvolver as argumentações e demonstrações segundo uma lógica não necessariamente linear nem dedutiva, mas que podem ser aberta, clara e racional, graças à multiplicação dos vínculos hipertextuais, ou seja, trata-se de um processo de escrita/leitura realizado no ciberespaço não determinado. (CHARTIER, 2003)

Por sua vez, Nicolaci-da-Costa (2006) reflete que a revolução digital inaugura a possibilidade de diálogo entre escritores e leitores; ora, trata-se de um grande personagem propiciador de mudanças nas práticas de escrita/leitura, permitindo supor uma nova caracterização do escritor/ leitor diante do mar da web. Nesse processo, examina-se uma escritura polifônica (Bakhtin, 2000), uma vez que vários personagens têm vozes nas histórias contadas pelos sujeitos nessa página virtual, como se pode examinar a seguir.

Revista Caminhos da Educação: diálogos, culturas e diversidades. CAEDU/UFPI 110

Teresina, Brasil, v. 1, n. 2, p. 102-116, maio/agosto de 2019.

ISBN: 2675-1496 DOI: https://doi.org/10.26694/caedu.v1i2.9693 


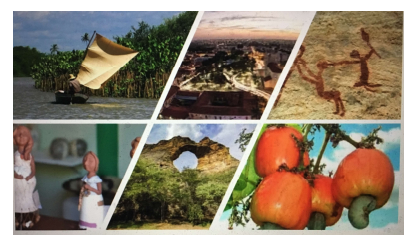

ISBN: 2675-1496 DOI: https://doi.org/10.26694/caedu.v1i2.9693

Figura 3- Adaptação da Página Fanfiction "Todo mundo odeia o Chris"

\section{Fanfiction}

Categorias Português Liga dos Betas Recentes

"C-Chris?" Viro, curioso, e dou de cara com uma garota loira que, se eu me lembrava bem, era da turma $\mathrm{C}$

"Ah... oi?" Ela olhava para o chão e torcia um pouco as mãos, parecendo nervosa

"E-eu q-queria sabe-er se não quer i-ir ao b-baile comig-go?" O QUÊ?!

Entrei em choque por alguns segundos e não respondi, o que fez ela finalmente olhar para mim. Pelo canto dos olhos, pude ver um Greg tão chocado quanto eu.

"A-ah..." tentei encontrar voz para responder. "Eu... sinto muito, mas só tem uma pessoa com quem eu gostaria de ir ao baile. Desculpa."

Ela me olhou com os olhos tristes, e eu me senti mal por rejeitá-la - eu sabia como doía -, mas eu não podia agir de outra forma. Após alguns instantes ela assentiu e se despediu com um sussurro. Observei-a ir embora com certo peso na consciência, mas não tinha jeito. Só acordei quando Greg me cutucou as costelas.

"A gente não tá sonhando não, né?" Balancei a cabeça.

Fonte: $<$ https://fanfiction.com.br/todomundoodeiaochris/>Acesso em 06/11/2019

O trecho acima postado pelo usuário Bennet na página da Fanfiction procura narrar outra história vivida por Chris além dos episódios televisivos; o capítulo trata de um possível roteiro não habitual na vida; trata-se de um convite feminino ao amigo para juntos irem ao baile do nono ano do colégio. Se os sujeitos procuram convidar as suas amigas especiais para poder acompanhá-los no evento festivo, nessa história, uma jovem convida o Chris para a festa. O curioso é que Chris rejeita o pedido da jovem. Nessa acepção, pode-se refletir que os gêneros literários nas inovações tecnológicas (Machado, 2007) deixam cair por terra os hábitos e costumes vistos e lidos em outras narrativas; em outras palavras, as artes midiáticas também são a expressão da criação artística, exprimindo a sensibilidade e o conhecimento do início do terceiro milênio.

Revista Caminhos da Educação: diálogos, culturas e diversidades. CAEDU/UFPI 111

Teresina, Brasil, v. 1, n. 2, p. 102-116, maio/agosto de 2019.

ISBN: 2675-1496 DOI: https://doi.org/10.26694/caedu.v1i2.9693 


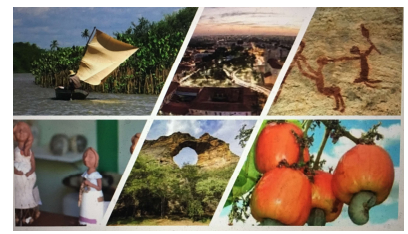

ISBN: 2675-1496 DOI: https://doi.org/10.26694/caedu.v1i2.9693

Quando o tema são as obras de ficção literária nas páginas do Fanfiction, criadas pelos próprios sujeitos, que são admiradores de alguns personagens, há de se ver com outros olhos esses gêneros textuais, remetendo-nos aos estudos de Bobbio (1997), ao sugerirem que o sujeito é aquilo que realiza, ama e esquece; logo as dimensões da cultura e das representações seguem nas veredas dessa reflexão.

A virada do século $\mathrm{XX}$ observou paródias, revisões, ressignificações nos gêneros textuais virtuais, sobretudo com a implementação do WWW (World Wide Web); as páginas convidam os navegantes, impulsionando vários sujeitos à participação; é possível refletir que a cultura dialoga com os usuários, e eles postam com os seus estilos próprios de linguagem.

Há de se destacar a interatividade (Lévy, 1999) e a representação dos sujeitos (Chartier, 2003) nas suas práticas do cotidiano (Certeau, 2010), ou em outras palavras, histórias que dialoguem com a sensibilidade dos usuários, como é possível examinar a seguir.

Figura 4- Adaptação da Página Fanfiction "Todo mundo odeia o Chris"

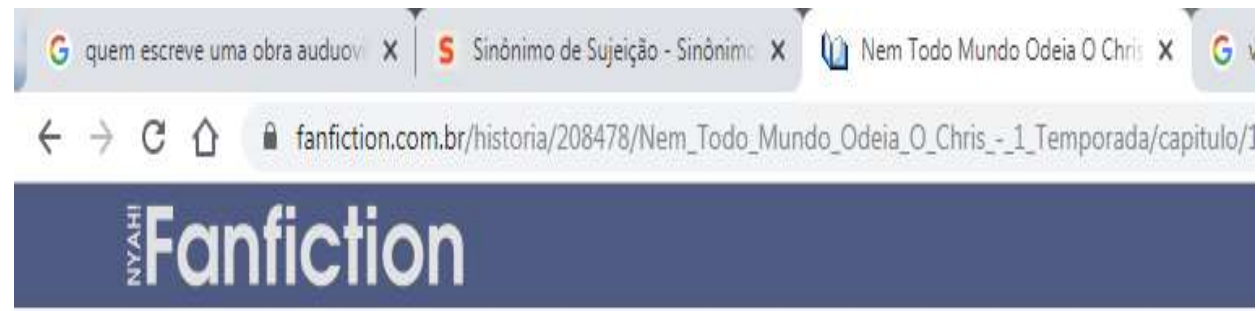

Categorias Português Liga dos Betas Recentes

O Chris é muito engraçado. É só uma garota falar 'oi' pra ele que ele já se apaixona
por ela. É hilário. Não sei como ele não se apaixonou por mim, mas ainda bem que não.
Esse negócio de amor é uma furada e eu não ia gostar de dar um pé nele. Mas não vou
negar que sinto falta de alguém que cuide de mim. Ele de vez em quando faz isso. É meu
melhor amigo.
E por falar em melhor amigo, meu projeto tá a todo vapor. Logo o Chris vai ter uma
surpresa ótima. Pelo menos eu acho que ele vai gostar. Eu não vou ter problemas com
isso, mas se ele achar que é muito invasivo eu dou um jeito de desfazer. Mas eu só vou
saber isso quando eu terminar. Mãos à obral

Fonte: $<$ https://fanfiction.com.br/todomundoodeiaochris/>Acesso em 06/11/2019

Revista Caminhos da Educação: diálogos, culturas e diversidades. CAEDU/UFPI 112

Teresina, Brasil, v. 1, n. 2, p. 102-116, maio/agosto de 2019.

ISBN: 2675-1496 DOI: https://doi.org/10.26694/caedu.v1i2.9693 


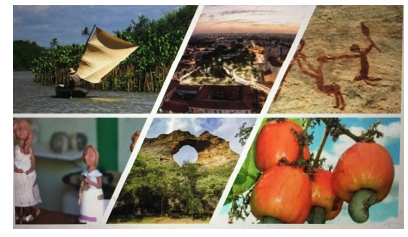

ISBN: 2675-1496 DOI: https://doi.org/10.26694/caedu.v1i2.9693

O trecho da narrativa acima procurou inspirar o usuário Ray a se aproximar de um tema muito comum para os adolescentes que são as experiências com a paixão, as emoções, as amizades, as sensibilidades juvenis, as surpresas amorosas vividas pelos sujeitos. Quem disse que a poesia tem apenas uma manifestação, exteriorização? Antonio (2008) entende que a linguagem tecnopoética também tem a sua rubrica, produz movimentos internos, interacionais, hipermidiáticos, resultando na poesia intratextual e intertextual.

$\mathrm{Na}$ contramão dessa reflexão, Machado (2007) sugere que a demanda comercial e o contexto industrial não necessariamente inviabilizam a criação artística, o que nos leva a refletir que, talvez, se trate de uma nova relação com as tecnologias e a sociabilidade, configurando-se em uma cultura contemporânea.

As mais variadas manifestações narrativas sempre possibilitaram interações dos sujeitos através da imaginação, gerando uma gama diversificada de leituras de mundo a partir de uma história. Nessa acepção, é possível refletir que as narrações no ambiente digital oferecem aos usuários/interlocutores a possibilidade de se transportarem para outros mundos, sem sair do lugar. (LÉVY ; LEMOS, 2010)

O desejo de procurar viver um faz de conta, um sonho, uma fantasia, quem sabe, seja a mola propulsora dos sujeitos/usuários na página Fanfiction da internet, na tentativa de se poder criar, participar e (re)significar as histórias com os seus personagens televisivos favoritos. Por que não também poder trabalhar com esta dimensão na escolarização?

Considerações finais

Nas margens que aproximam as novas tecnologias e a produção de textos surgem novos modelos de gêneros textuais, desafiando os parâmetros vigentes para tornarem visíveis esses canais sobre as práticas de escrita dos sujeitos. Em face da multiplicação de novos formatos em circulação (Castells, 1999), acentua-se a necessidade de se (re)pensarem atribuições de valores para esses novos modelos de comunicação e expressão, surpreendendo os usuários com interatividade, imersão, interface no universo virtual, passando a integrar perspectivas que antes quem sabe não teriam sido refletidas.

Estas novas práticas de escrita que as novas gerações vêm desenvolvendo além dos muros escolares, interagindo entre pares, muitas vezes em situações de aprendizagem colaborativa, utilizam os diferentes dispositivos midiáticos. Tais artefatos tecnológicos também têm as suas linguagens; não sendo neutros (Barthes, 1999), os seus dispositivos instrumentais, mercantis, publicitários também dialogam (Bakhtin, 1998) com as mídias televisivas (Fischer, 2001; Chauí, 2006; Ferrés, 1998), contribuindo também para as aprendizagens e leituras de mundo dos sujeitos.

Revista Caminhos da Educação: diálogos, culturas e diversidades. CAEDU/UFPI 113

Teresina, Brasil, v. 1, n. 2, p. 102-116, maio/agosto de 2019.

ISBN: 2675-1496 DOI: https://doi.org/10.26694/caedu.v1i2.9693 


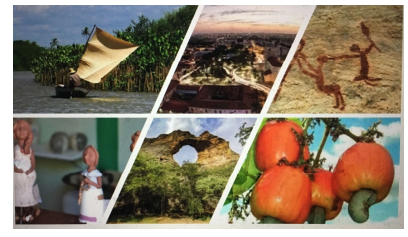

ISBN: 2675-1496 DOI: https://doi.org/10.26694/caedu.v1i2.9693

Por meio de instrumentos materiais tais como a tela, o teclado, o mouse e imateriais, a saber, as linguagens de comando, o receptor se transforma em usuário e organiza a sua navegação como quiser em um campo de possibilidades cujas proporções são infinitamente grandes para lhes dar a possibilidade de serem os autores das histórias (re)significadas a partir dos episódios televisivos, (re)escrevendo com a tinta eletrônica, refletindo sobre os temas do cotidiano nas suas narrativas numa multiplicidade de pontos de vista.

Mas será que isso é o fim? As práticas de escrita acenam por atenção e criatividade nos nossos dias. Não podemos nos esquecer do ritmo acelerado da cibermídia, que a cada dia se (re)inventa com outros portais, sites, páginas, produções escritas no âmbito digital. Nos horizontes dos outros repertórios textuais digitais, cujos atributos se encontram na exploração das possibilidades da inteligência artificial, na web semântica (Santaella, 2004), é possível refletir que a conexão entre os sujeitos e a troca de textos, histórias, narrativas, linguagens, de qualquer lugar para qualquer outro, indique que cada vez mais a comunicação humana, como na inspiração de Gilberto Gil, possa "promover um debate, fazer [...] um barco que veleje nesse infomar e aproveite a vazante da infomaré". Que a abertura desses canais, veículos, suportes, caminhos plurais possam nos oferecer intercâmbios de vozes, representações, opiniões, questionamentos, pontos de vista e visões de mundo.

Referências bibliográficas

ANTONIO, Jorge Luiz. Poesia eletrônica: negociações como os processos digitais. Belo Horizonte: Veredas \& cenários, 2008.

AYMARD, Maurice. "Amizade e convivialidade”. In: CHARTIER, Roger. História da vida privada, 3: da Renascença aos Séculos das Luzes. São Paulo, Companhia das Letras, 2009. p. 455-499.

BARTHES, Roland. O prazer do texto. São Paulo: Perspectiva, 1999.

BAKHTIN, Mikhail Mikhailovitch. Marxismo e Filosofia da Linguagem. São Paulo: Hucitec, 1999.

Hucitec, 1998.

Questões de Literatura e Estética - A Teoria do Romance. São Paulo: . Estética da criação verbal. São Paulo: Martins Fontes, 2000.

Revista Caminhos da Educação: diálogos, culturas e diversidades. CAEDU/UFPI 114

Teresina, Brasil, v. 1, n. 2, p. 102-116, maio/agosto de 2019.

ISBN: 2675-1496 DOI: https://doi.org/10.26694/caedu.v1i2.9693 


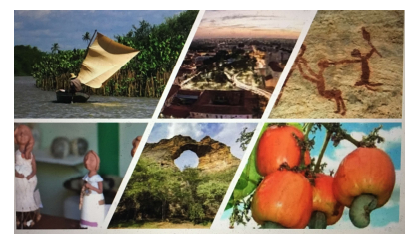

ISBN: 2675-1496 DOI: https://doi.org/10.26694/caedu.v1i2.9693

BOBBIO, Norberto. O tempo da memória - de senectude e outros escritos autobiográficos. Rio de Janeiro: Campus, 1997.

CASTELLS, Manuel. A sociedade em rede: a era da informação-economia, sociedade e cultura. São Paulo: Paz e Terra, 1999.

CERTEAU, Michel de. A invenção do cotidiano: artes do fazer. Petrópolis, Ed. Vozes, 2010 .

CHARTIER, Roger. Formas e sentido. Cultura escrita: entre distinção e apropriação. São Paulo: Mercado de Letras, 2003.

CHAUÍ, Marilena. Simulacro e poder: uma análise da mídia. São Paulo: Perseu Abramo, 2006.

CRYSTAL, David. A revolução da linguagem. Rio de Janeiro: Jorge Zahar Ed, 2005.

FERRÉS, Joan. Televisão Subliminar: socializando através de comunicações desapercebidas. Porto Alegre: Artmed, 1998. . Televisão e Educação. Porto Alegre: Artes Médicas, 1996.

FIORIN, José Luis. Elementos de análise do discurso. São Paulo: Contexto, 2008.

FISCHER, Rosa Maria Bueno. Televisão de Educação: fruir e pensar a TV. Belo Horizonte: Autêntica, 2001.

LEMOS, André. Cibecultura, tecnologia e vida social na cultura contemporânea. Porto Alegre: Editora Sulina, 2008.

LÉVY, Pierre. As tecnologias da inteligência: o futuro do pensamento na era da informática. São Paulo: Editora 34, 1999.

; LEMOS, André. O futuro da Internet: em direção a uma ciberdemocracia planetária. São Paulo: Paulus, 2010.

MACHADO, Arlindo. Arte e mídia. Rio de Janeiro: Zahar, 2007.

MARCONDES FILHO, Ciro. Televisão: a vida pelo vídeo. São Paulo: Moderna, 1995.

Revista Caminhos da Educação: diálogos, culturas e diversidades. CAEDU/UFPI 115

Teresina, Brasil, v. 1, n. 2, p. 102-116, maio/agosto de 2019.

ISBN: 2675-1496 DOI: https://doi.org/10.26694/caedu.v1i2.9693 


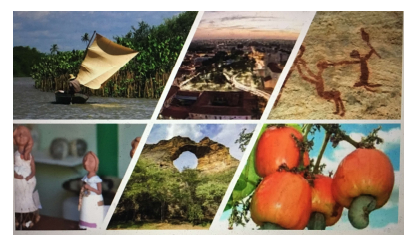

ISBN: 2675-1496 DOI: https://doi.org/10.26694/caedu.v1i2.9693

MARTÍN-BARBERO. Dos meios às mediações: comunicação, cultura e hegemonia. Rio de Janeiro: Edufrj, 1997.

MARCUSCHI, Luiz Antônio. Produção textual, análise de gêneros e compreensão. São Paulo: Parábola Editorial, 2008.

NICOLACI-DA-COSTA, Ana Maria (org). Cabeças Digitais: O cotidiano na era da informação. Rio de Janeiro: Ed.Pucrio, 2006.

PAIVA, Jane. Os sentidos do direito à educação para jovens e adultos. Petrópolis, Rio de Janeiro: DP et alii, 2009.

ROSA, João Guimarães. Tutaméia. Rio de Janeiro: Nova Fronteira, 1985.

SANDMANN, A. J. "Polissemia e Homonímia". In: NEVES, M. H. de. Descrição do Português. Revista do Curso de Pós-graduação em Linguística e Língua Portuguesa. Ano IV, n. 1. São Paulo: Unesp, 1990, pp. 98-127.

SANTAELLA, Lúcia. Cultura e artes do pós-humano. São Paulo: Paulus, 2003.

Paulus, 2004.

. Navegar no ciberespaço: o perfil cognitivo do leitor imersivo. São Paulo:

SIMÕES, Robson Fonseca. Memórias digitais: histórias escolares nas comunidades do Orkut. Appris: Curitiba, 2018.

SOARES, Magda. Letramento: um tema em três gêneros. Belo Horizonte: Autêntica, 2009.

Recebido: 01/07/02019

Aprovado: 18/09/2019

Revista Caminhos da Educação: diálogos, culturas e diversidades. CAEDU/UFPI 116

Teresina, Brasil, v. 1, n. 2, p. 102-116, maio/agosto de 2019.

ISBN: 2675-1496 DOI: https://doi.org/10.26694/caedu.v1i2.9693 